\title{
Directions for Supply Chain Strategic Coordination: Discussion and Proposals
}

\author{
Pedro Domingos Antoniolli \\ Methodist University of Piracicaba - UNIMEP, Brazil \\ E-mail: pedroantoniolli@yahoo.com.br \\ Carlos Roberto Camello Lima \\ Methodist University of Piracicaba - UNIMEP, Brazil \\ E-mail: crclima@unimep.br
}

Received: May 10, 2014

doi:10.5296/jmr.v6i3.5609
Accepted: May 30, 2014

Published: July 1, 2014

URL: http://dx.doi.org/10.5296/jmr.v6i3.5609

\begin{abstract}
Global companies and markets require greater flexibility and agility to compete, leading to supply chains (SC), structures in which each link is responsible for adding value through the operations it performs and aiding them to focus on optimization of operations and integrated logistics. From this productive arrangement, competition occurs now among SCs and no longer among individual companies. The companies in an SC reap the benefits of large-scale production through differentiation, minimizing the traditional trade-off. In this paper, fundamentals for managing SC operations relying on a manufacturer setting of competitive priorities are assessed. Agility is the main criterion, a key condition for the competitiveness. From an extensive literature review of supply chain management (SCM), definition of structural and infrastructural characteristics, strategies and their hierarchy, and a detailed analysis of the manufacturing strategy is discussed. Finally, some directions for SCM strategic management are proposed.
\end{abstract}

Keywords: Agility, Manufacturing Strategy, Supply Chain Performance, Strategy, Strategic Coordination, Supply Chain Management. 


\section{Introduction}

According to Hill (1998), globalization can be understood as a set of convergent changes leading to a more integrated and interdependent world where commerce, finance, markets and production no longer have a purely local scope. The movement was driven by several factors, such as increasing market deregulation, falling trade barriers, and a changing consumers' profile, which means that firms need to offer higher added value. This scenario requires that enterprises compete intensely to survive in such environment. Vertical integration usually causes operational limitations, so organizations seek strategic alliances in order to obtain higher levels of performance by constructing and managing virtual structures called supply chains (SC) (Lambert and Cooper, 2000; Rainbird, 2004; Croxton et al., 2008; Christopher, 2011). Cooper et al. (1997) pointed out that logistics development was one of the causes of the emergence of SCs and that the movement evolved through four distinct phases: targeted action, tight integration, flexible integration, and strategic integration, made possible by supply chain management (SCM). In addition, Kaplan and Norton (1996) pointed out that the effectiveness of the enterprises is based on a set of operating assumptions regarding competing and operating integrated processes and involving functional specialization with agility, efficiency and quality.

Thus, competition among individual enterprises is no longer enough since SCs are now competing, and they must be agile and responsive in order to fully meet the expectations of the end customer (Rice \& Hoppe, 2001). Additionally, Rungtusanatham et al. (2003) argued that integration between supplier and customer provides a means for both to obtain additional external resources. Slack and Lewis (2002) corroborated this view and considered an approach based on resource allocation and use as a source of an operational advantage. Mahdavi et al. (2009) considered globally optimized supply chain operations to be a key issue because coordination is hampered by the complexity and uncertainty that characterize such chains. Christopher (2011) pointed out that time is also a critical issue in supply chain management since the consumer is increasingly willing to accept substitute products when a desired product is not available, and the perceived added value for such a client is important in order to gain his or her loyalty. According to Porter (1985) and Abdulmalek et al. (2007), value is defined as the amount the consumer is willing to pay for a product or service based on its offered utility. Hansen and Mowen (2001) added that competitive advantage is achieved by "creating a better value for the client at an equal or lower cost than that offered by competitors". Rother and Shook (2003) defined a value stream as all essential activities in a set of processes through which a product passes, which may or not create value. Croxton et al. (2008) complement, explaining that variability reductions contributes to an increased accuracy of the design, thus reducing costs, while increasing the flexibility helps the SC to quickly respond to internal and external events.

Savaris and Voltolini (2004) stated that "You cannot manage what you do not know, cannot know what you do not control, cannot control what you do not measure". To measure the effectiveness of SC processes and strategies, it is important to apply a performance measurement system (MDS) composed of relevant indicators that can provide data that will guide one to adjust the process and/or the strategy in use. Beamon (1999) stated that 
indicators should define the aspects to be measured and be used as a foundation for this measurement.. They must provide breadth (cover all important and relevant aspects), universality (be comparable under different operating conditions), measurability (be possible to measure) and reliability (match the organization's goals).

This article aims to identify the key elements that enable competitive differentiation in supply chains and to propose a set of techniques and practices for the strategic management of these productive configurations. Some basic assumptions were considered: i) Operational and strategic participants of an SC must be integrated; ii) Agility is a differentiating factor in an SC; iii) Measuring performance is the first step to optimizing an SC. The goal was to corroborate the relevance of the concepts presented in the literature on SC strategy and proposals for applying these concepts to the existing chains.

\section{Supply Chains (SCs) and Supply Chain Management (SCM)}

There is no consensus regarding the definition of a supply chain (SC). To Beamon (1999), it is an integrated process in which raw materials are transformed into finished products and shipped to customers with the participation of more than one organization in this process. Pires (2004) defined SC as a set of autonomous or semi-autonomous companies, which are responsible for obtaining, producing, and delivering a product or service to the customer. Towill et al. (2002) and Lee and Wang (2001) state that a supply chain consists of integrated suppliers' and customers' organizational processes, aiming to improve the performance of all SC participants. Lambert et al. (1998) stated that an SC is a network of companies with multiple business relationships. In this structure, each link in the chain provides facilities so the product obtains value along the chain. For the Council of Supply Chain Management Professionals (2013), SCM encompasses the planning and management of activities related to the purchase and supply goods, as well as processing and logistics management, which includes coordination and collaboration with logistics partners. Wanke (2010) stated that the following processes are fundamental to effective SC management: i) Customer Relations; ii) Customer Service; iii) Demand Management; iv) Customer Orders; v) Administration of Productive Process; vi) Purchasing and Supplies; vii) New Product Development.

The integration among customers and suppliers in SC is hindered by the complexity existing in an alignment with the strategic priorities of these partners and the degree of adherence to these priorities in reaching the goals of the SC (Wanke, 2010). There are some important factors that should be stressed. First, the differences in the structures of fixed and variable costs of operations mean that companies closer to the primary sectors of the economy (e.g., agriculture) and therefore farther from the end customer have a higher proportion of fixed costs compared to variables. Firms closer to the end customer are structured with predominantly variable costs and discrete manufacturing processes requiring little need for capital. Their strategies are based on flexibility that allows them to respond and they favor variations of mix and volume. Wanke (2010) also related the cost structure of a firm to its flexibility regarding speed, range and volume. Thus, companies with a cost structure predominantly made up of fixed costs are less flexible, with longer response times, and they usually have fewer technological resources available to help them meet variations and volumes. Coupled with the complexity existing in the strategic alignment of participants in 
the supply chain is the realization that consumers are more informed and demanding with respect to the products and services received (Christopher, 2011). Therefore, it is important that the SCM focuses on enabling collaboration, cooperation, integration, and synergy among SC participants.

SCM can have a broader definition that includes not only logistics but also integrated processes, structures, systems, and strategies in order to obtain synergy among firms for the generation of added value in products delivered to the final customer (Vollman \& Cordon, 1996). Another author expanded the definition to encompass the processes of reverse logistics, which is more important today (Baatz, 1995). Another definition was provided by Lee and Billington (1992): SCM focuses on processes, technologies and skills usage in order to increase competitiveness through coordination of manufacturing, logistics, distribution and transportation within a SC. SCM can also be defined as the management of physical, logical and financial flows in networks of organizational relationships jointly thus adding value and achieving customer satisfaction (Stock \& Boyer, 2009).

\subsection{Practices to improve Supply Chain performance}

Some practices are used to simplify and make SC more efficient. As an example, companies are restructuring and reducing the number of suppliers and consequently deepening relationships with those whose products, services and processes have greater importance within the value chain and spreading concepts such as outsourcing, strategic partnerships and distinctive competencies. Outsourcing involves partnership and complicity with one or more SC suppliers. This trend is being scrutinized in the automotive sector, in which most of the activities were transferred to the first-tier suppliers (Collins et al., 1997).

Information sharing and integration of infrastructure with customers and suppliers allows deliveries just-in-time (JIT) and reduction of inventory levels. Such integration is usually obtained through information systems (SI) participants' integration in the following ways: i) Electronic Data Interchange (EDI), which allows document sharing electronically; ii) Efficient Customer Response (ECR), which is used on an automatic replenishment basis. This practice is more often applied to SC final links (downstrains), which means closer to the end customer (downstream). According to Wanke (2010), the ECR originated in the USA food sector, in which supermarkets and manufacturers cooperated in five areas: sharing real-time data management, product categories, continuous replenishment of inventory, activity-based costing, and products and processes standardization; iii) Quick Response (QR): according to Wanke (2010), the basic logic of QR is that suppliers have access to data collected directly from their customers' selling points, so they can synchronously integrate their production operations and inventory to make sales to these customers. The information related to lower customer inventory is received at the time of sale, which eliminates the lead time for identifying the demand, significantly improves the service level, and reduces the need for inventories; iv) Continuous Replenishment (CR): in CR, also called Rapid Response, suppliers receive data directly from points of sales. This information is used to prepare regular shipments to the customer in order to meet required inventory levels and thus ensure 
that inventory fluctuations remain within the minimum and maximum limits, considering seasonality, promotions, and any changes in customers' shopping behavior (Wanke, 2010).

There is a greater involvement of participants in both product development and problem solving. This category includes early suppliers' involvement (ESI) in product development with the goal of anticipating possible design problems and decreasing the time it takes to bring a product to market (TTM). This practice increases the possibility of partnership consolidation throughout a product's lifecycle (Pires, 2004). This also includes the concept of In Plant Representatives (IPR), whose objective is to allocate people to partners to ensure that processes are suited to those required by the company. Additionally, products are designed to allow flexibility in handling during logistical processes. Vendor Managed Inventory (VMI) enables agility and integration of logistical and financial flows, since a customer usually pays for a product only after it is sold (Darwish \& Odah, 2010; Pasandideh, Niaki \& Nia, 2011).

The final configuration of the product is postponed until it reaches the nearest point at the end of the chain (decoupling point) and is consequently closer to the end customer. This practice is called Postponed Manufacturing and aims to give greater flexibility to in-process materials stocks and consequently reduce their levels. This practice is used in collaboration with mass customization in SC, which implies that a product can meet different customers' expectations after being slightly modified. This practice can decrease the impact of differentiation and cost trade-offs.

Continuous Improvement of Industrial Processes is implemented in response to the need for greater competitiveness through effective management of production resources. The term continuous improvement has often been associated with the Total Quality movement and Six Sigma methodologies. However, the concept can be applied to other approaches. Caffyn (1999) considered continuous improvement to be the process of incremental innovation by the entire organization. Mahdavi et al. (2009) and Song (2013) stated that global SC optimization is the main issue to be explored by company managers because coordination is damaged by complexity and uncertainty that characterizes such supply chains. They explained that when a system is not coordinated, optimizations and operations of SC participants occur in isolation, and there is no consideration of their impact on others. This often results in higher inventory and demand variations across the SC, thus reducing performance.

\section{Strategic Management of SCM}

The strategic management of an SC should effectively address an SCM's critical elements in order to discover details about its execution (Fisher et al., 2010). One of the important elements is demand management. If this is done well, prediction errors will be minimized, uncertainties concerning the management of productive capacity will be reduced, and, therefore, inventory needs will decrease. On the other hand, if it is not managed effectively, demand amplification will be generated along the chain, a phenomenon known as the "bullwhip effect," which occurs when the vendor orders have greater variation than those of the downstream customer, and this distortion is propagated and amplified upstream along the SC (Lee, 1997; Metters, 1997; Van Landeghem \& Van Maele, 2002). Lee et al. (1997) 
estimated that demand amplification along the SC can result in cost increases of $12.5 \%$ to $25 \%$ for the chain as a whole.

As longer stated by Skinner (1969), if a firm wants to be considered competitive, operations decisions must be carefully aligned with business strategy, and these decisions influence the logistics lead times. Therefore, inventory management and demand suffer negative impacts caused by the poor management of these operations. Hax and Golovin (1978) emphasized that decisions made by manufacturing managers affect an organization's strategic, tactical, and operational dimensions and defined each type. Strategic investment decisions especially impact infrastructure and resource acquisition, alliances, product development, and other factors with a long-term focus; Tactical decisions about aggregate production planning, distribution, and resource allocation influence operating effectiveness in the medium term; Operational decisions about production details focus on minimizing local costs in the short term.

The SC inventory systems are classified, according to Verwijmeren et al. (1996), into two types: i) Base Control of Stock (BCS) systems operate with regard to each of the SC inventory points and are based on actual customer demand rather than in support of the demand generated by the SC at the next point. Instead of managing the inventory level local systems, BCS manages the inventory level of a full-point stock; ii) Planning Requisition Line (LRP) systems also make full use of inventory levels using time-based forecasting regarding MRP systems. In contrast, the LRP explore not only expected information requests but also information on stock levels at points downstream and upstream.

Based on the results of studies focused on SC and decentralized distribution, in which participants belong to different companies, Wang et al. (2004) stated that three components must be present: i) A plan to coordinate decisions and activities of the SC members; ii) A framework for sharing information among members; iii) An incentive scheme to allocate the benefits of coordination.

According to Rice and Hoppe (2001), one of the critical issues in SCM is the development of skills that enable the integration of processes and activities along the SC. Additionally, the financial-economic factor should be the focus of analysis since traditional accounting does not reflect the flow of materials that are not aligned to customer service process orientation. Regarding this issue, Christopher (2011) stated that traditional accounting systems do not offer the possibility of analyzing costs and revenues by type of customer or distribution channel, which are crucial issues one needs to address in order to measure SC financial performance. Christopher stated that the "mission" concept is, in the SC context, "a set of goals for customer service to be achieved by the system in the context of specific product / market." Thus, missions are dependent on product type and limit service level and market characteristics in which the SC is located.

Christopher (2011) added that a mission, because of its procedural nature, crosses the internal borders of traditional enterprise and, therefore, has limitations if financial performance is measured by traditional methods of costing and profitability, which are directed to products and departments. Then, the author has stated that quality has to be considered in value 
definition. Regarding quality, Christopher and Holweg (2011) considered tangible elements such as functionality, performance and adherence to technical specifications of the product. He stated that service can be understood as "availability, support and commitment provided to the customer." For the cost dimension, he suggested considering all elements related to the transaction with the customer. Finally, he stated that time is connected to the lead time required for the client.

Christopher (2011) presented the following value drivers for shareholders, which are directly or indirectly affected by logistics and SCM strategy: i) Revenue Growth: considers the impact that logistics service may have regarding sales volume and customer service.; ii) Reduce Operating Costs: there is potential reduction of operating costs into SCM by improvements in logistics and SCM appropriate strategy. In this sense, the quality of SC relationships helps form more lasting partnerships based on cooperation and collaboration. Additionally, the establishment of analysis and end-to-end processes provides opportunities to reduce non-value-added activities and generate new logistics methods. Thus, upstream logistics costs represent a significant portion of the SC total costs; iii) Efficiency of Fixed Capital: because logistics requires intensive use of fixed assets, it requires high investments, which sometimes do not translate into financial returns. Thus, alternatives must be sought to reduce or immobilize fixed assets by using lease practices; iv) Working Capital Efficiency: a long SC generates more inventory needs. Thus, increased investment in working capital is requested. Therefore, managers have attempted to reduce the order cycle by establishing lean chains that eliminate non-value-added activities and, consequently, the need for capital.

Organizations compete considering their abilities and skills. Thus, the company creates superior value by running processes differently, including product development activities, forming relationships with suppliers, and order fulfillment. In this sense, Value Management (VM) becomes a convergent paradigm in SCM because its focus is on policy making in projects and processes. VM aims to increase the value, not reduce costs; then, value is generated by the increased importance of functions in relation to their costs Hammersley, 2002).

\section{SCM Strategic Management Proposals}

Slack and Lewis (2002) argued that a functional strategy (including those used in manufacturing) includes the management of resources and processes for producing goods and/or services and is present in all organizations. Such operations can be decomposed and sometimes are part of network operations (e.g., supplies, production, resources) to serve internal and external customers. They explained that managers should understand the responsibilities associated with each element of these operations, regarding existing resources (capacity, technology, supply networks, organization and development, which give rise to resources competence) and performance objectives (qualifying criteria and classifiers).

Wheelwright (1978) and Hayes and Wheelwright (1984) stated that the process of drafting the strategy should be formalized and that its formulation depends on the unfolding of manufacturing in a number of decision areas, for example, measurable performance objectives, which make explicit goals of manufacturing achievable. Hayes and Wheelwright 
(1984) and more recently Slack and Lewis (2002) argued that manufacturing strategy can be adjusted to support a company's business strategy based on performance objectives and decision areas.

The first strategic decision level, according to Miller and Roth (1994), occurs in performing the tasks of manufacturing (i.e., considerations regarding cost, quality, flexibility and reliability). At the second strategic level, Hayes and Wheelwright (1984) distinguished between structural and infrastructure decisions that determine the practices to be applied in the design of manufacturing systems and operations. Slack and Lewis (2002) added to this approach, stating that these decisions are applied in four main areas: capacity, supply chains, technology and innovation, and organization and structure.

According to McKone-Sweet and Lee (2009), the strategy of SC can be defined as "choosing a set of skills that are developed through a standard investment over time, which cannot be easily imitated or acquired commercially”, and added that no substitute products can be found. Jüttner et al. (2007) argued that today the customer is more demanding with respect to services rendered. Thus, four principles should be considered as targets to be achieved in the SCM: i) Responsiveness is the ability to understand how SC responds to customer demands under increasingly shorter deadlines with greater agility; ii) Reliability comes into play because inventories exist as protection mechanisms, and with greater process variability, higher inventory levels are required. Thus, to improve SC reliability, it is essential to reduce process variability; iii) Resilience is necessary due to market turbulence, which may create risks for SC operations that experience process disruptions or the possibility of discontinuities. Therefore, cost minimization and service level optimization are SCM goals; iv) Relationships between the buyer and supplier must be considered partnerships since they can share costs and achieve synergies, creating lasting benefits for both parties because this alliance hinders competition.

According to Slack and Lewis (2002), the company should identify what factors and qualifiers influence demands for its products and services and constantly monitor them because over time competitors may imitate them, and the winners can become qualifiers. Although coordination and configuration should be considered together in formulating a strategy, the method illustrated in Figure 1 is proposed for coordinating SC, which is an adaptation of the models produced by Skinner (1969), Hill (1998), Ferdows and De Meyer (1990), Slack and Lewis (2002).

In this configuration, each SC link has its priorities and respective decision areas, which may or may not be convergent with the method arrangement, but for integrated SCM it is necessary to define a set of criteria (business drivers) and priorities that meet the cost, quality, flexibility and delivery criteria, and in each factor agility is considered to be a premise. These criteria are then ranked according to qualifiers and classifiers, and their actions and performance measures are linked. The goal is to formulate the SC strategy by considering the chain as a whole, linking this global strategy with one of each participant has. 


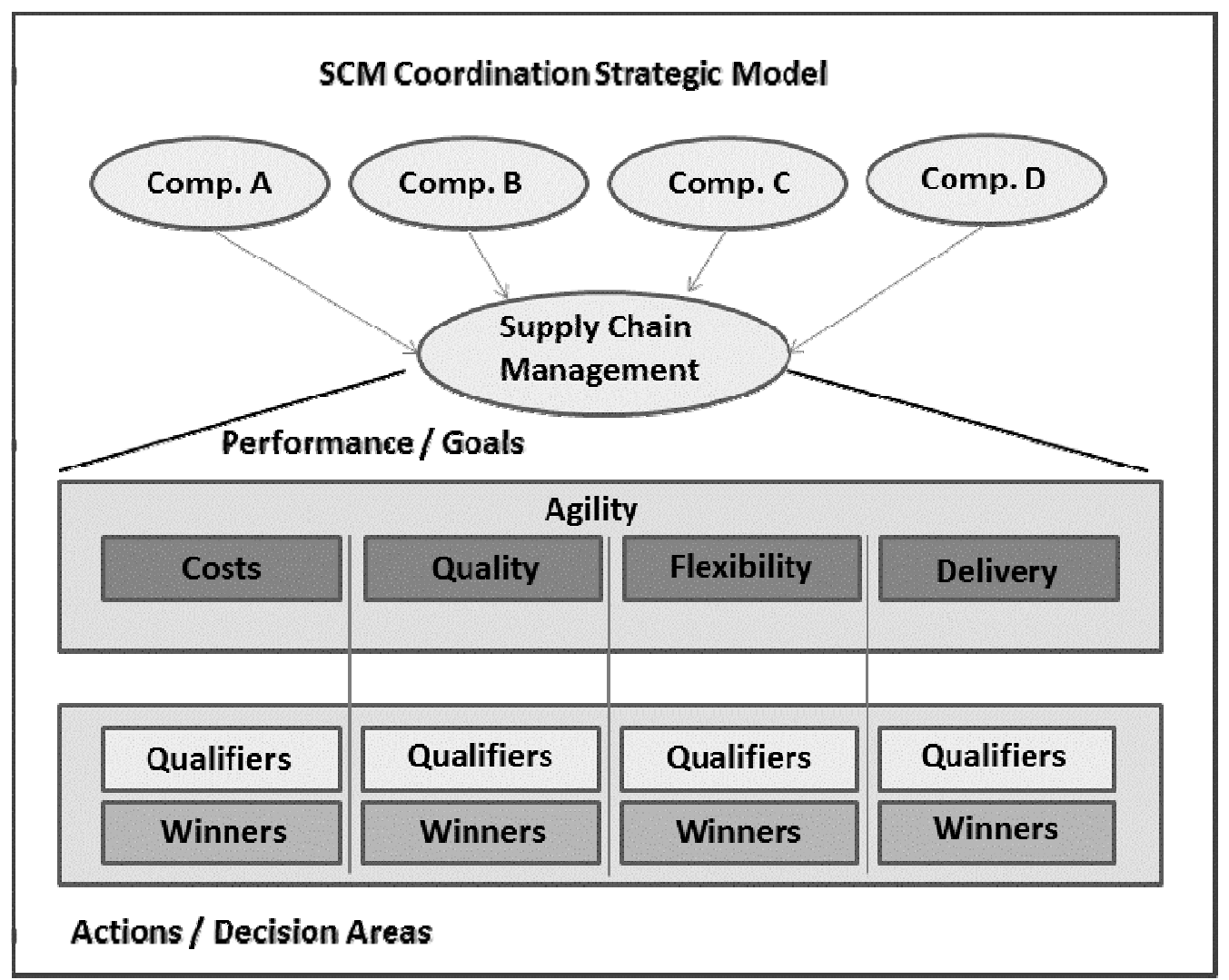

Figure 1. Directions for Operations Management of SC.

Source: Adapted from Skinner (1969), Hill (1998), Slack and Lewis (2002).

The approach to SCM performance measurement considered in this work is borrowed from Fantazy et al. (2009), who classified such measures in two dimensions: financial and non-financial. The financial measures considered are: i) Profitability Performance (NPP); ii) Sales Growth (SGP); The nonfinancial measures the authors considered are: i) Customer Satisfaction Performance (CSP), which is based on the concept of value, the degree to which customers perceive that the goods or services received are worth more than they paid; ii) Lead Time Performance (LTP), which is the time interval between the receipt of the request and delivery of the final product. Thus, the financial and non-financial performance dimensions are associated with types of flexibility, which leads to effective implementation of the strategy.

\section{Conclusion}

This paper presented information to show that in the current competitive environment, the value concept is central to the formulation of business strategies. Value is obtained by using internal resources and developing new skills, which are key elements of functional strategies, particularly in manufacturing and operations. Then, a literature review of supply chain (SC) and supply chain management (SCM), focusing on its features and requirements was performed. Subsequently, an analysis of those aspects to be considered when formulating SC strategy and management was discussed. Finally, important factors to be considered during the development of a strategy for managing the coordination of SC, using the elements of 
manufacturing strategy were stressed. To this end, an example was illustrated through an abstraction method, which aims to highlight the importance of concern for the formalization of measuring performance, and that may serve as a basis for decision making and to adopt actions that provide integrated management of operations of the SC without, however, creating conflicts with the particular strategies of each organization involved in the value network. It was not intended to establish comprehensive concepts regarding strategic models of coordination and implementation of SC operations but to present a real and practical application in SC. The main goal was to emphasize the importance of discussing the form and content of SC strategies, which offers a vast area of possibilities for research in the future.

This study was done based on an automotive supply chain, thus being a limitation for these concepts application. For future researches in this area, studies considering other supply chain industries, like pharmaceutical and food are recommended. Besides, studies with agility as basis for other supply chain strategic management (and also performance measure systems) are also needed.

\section{References}

Abdulmalek, F., \& Rajgopal (2007). Analyzing the benefits of lean manufacturing and value stream mapping via simulation: A process sector case study. International Journal of Production Economics, 107(1), 223-236. http://dx.doi.org/10.1016/j.ijpe.2006.09.009

Baatz, E.B. (1995). CIO 100 - Best practices: the chain gang. CIO, 8(19), 46-52.

Beamon, B.M. (1999). Measuring supply chain performance. International Journal of $\begin{array}{llll}\text { Operations \& } \quad \text { Production } \quad \text { Management, } & 19(3), \quad 275-292 .\end{array}$ http://dx.doi.org/10.1108/01443579910249714

Caffyn, S. (1999). Development of a continuous improvement self-assessment tool. International Journal of Operations \& Production Management, 19(1), 1138-1153. http://dx.doi.org/10.1108/01443579910291050

Christopher, M., \& Holweg, M. (2011). Supply Chain 2.0: Managing supply chains in the era of turbulence. International Journal of Physical Distribution and Logistics Management, 41(1), 63-82. http://dx.doi.org/10.1108/09600031111101439

Christopher, M. (2011). Logistics and Supply Chain Management (4 $4^{\text {th }}$ ed.). NY: Prentice Hall.

Collins, R., Bechler, K. \& Pires, S. (1997). Outsourcing in the Automotive Industry: from JIT to Modular Consortia. European Management Journal, 15(5), 498-508. ,http://dx.doi.org/10.1016/S0263-2373(97)00030-3

Council of Supply Chain Management Professional - CSCMP. (2013). Supply chain management definitions. available at http://cscmp.org/aboutcscmp/definitions.asp?XX=1 (accessed 28 April 2014)

Cooper, M.C., Lambert, D.M., \& Pagh, J.D. (1997). Supply Chain Management: More Than a New Name for Logistics. International Journal of Logistics Management, 8, 1-14. http://dx.doi.org/10.1108/09574099710805556 
Croxton, K.L., Lambert, D.M., Garcia-Dastugue, S.J., \& Rogers, D.S. (2008). The demand management process. In Lambert, D.M. Supply chain management: processes, partnerships, performance. Florida: Supply Chain Management Institute, pp. 87-104.

Darwish, M.A., \& Odah, O.M. (2010). Vendor managed inventory model for single-vendor multi-retailer supply chains. European Journal of Operational Research, 204(3), 473-484. http://dx.doi.org/10.1016/j.ejor.2009.11.023

Fantazy, K.A, Kumar, V., \& Kumar, U. (2009). An empirical study of the relationships among strategy, flexibility, and performance in the supply chain contex. Supply Chain Management: An International Journal, 14(3), 177-188. http://dx.doi.org/10.1108/13598540910954520

Ferdows, K., \& De Meyer, A. (1990). Lasting improvements in manufacturing performance: in search of a new Theory. Journal of Operations Management, 9(2), 168-184. http://dx.doi.org/10.1016/0272-6963(90)90094-T

Fisher, S.L., Graham, M.E., Vachon, S., \& Vereecke, A. (2010) Don`t miss the boat: Research on HRM and supply chains. Human Resource Management, 49(5), 813-828. http://dx.doi.org/10.1002/hrm.20386

Hammersley, H. (2002). Value Management in Construction. Value Management Limited, Hammersley.

Hansen, D.R., \& Mowen, M.M. (2001). Cost, Accounting and Control Management. São Paulo, SP: Thomson Pioneira.

Hax, A.C., \& Golovin, J. (1978). Hierarchical Production Planning Systems. In A.C. Hax (Ed.) Studies on Operations Management, North Holland, Amsterdan.

Hayes, R.H., \& Wheelwright, S.C. (1984). Restoring Our Competitive Edge: Competing through manufacturing. New York, NY: John Wiley.

Hill, C.W. (1998). International Business: Competing in the Global Marketplace. Chicago, IL: Irwin.

Jüttner, U., Christopher, M., \& Baker, S. (2007). Demand chain management-integrating marketing and supply chain management. Industrial Marketing Management, 36(3), 377-392. http://dx.doi.org/10.1016/j.indmarman.2005.10.003

Kaplan, R.S. \& Norton, D.P. (1996). The balanced scorecard: Translating strategy into action. Boston: Harvard Business School Press.

Lambert, D.M., Cooper, M.C., \& Pagh, J.D. (1998). Supply chain management: implementation issues and research opportunities. International Journal of Logistics Management, 9(2), 1-20. http://dx.doi.org/10.1108/09574099810805807

Lambert, D.M., \& Cooper, M.C. (2000). Issues in supply chain management. Industrial Marketing Management, 29(1), 65-83.

Lee, H. L., \& Whang, S. (2001). E-business and supply chain integration. Stanford Global 
Supply Chain Management Forum, November 2001, Stanford University.

Lee, H.L., \& Billington, C. (1992). Managing Supply Chain Inventory: Pitfalls and Opportunities. Sloan Management Review, 33(3), 65-73.

Lee, H.L., Padmanabhan, V., \& Whang, S. (1997). The bullwhip effect in supply chains”. Sloan Management Review, 38(3), 93-102.

M. Rungtusanatham, Salvador, F., Forza, C., \& Choi, T.Y. (2003). Supply-chain linkages and operational performance: a resource-based view perspective. International Journal of

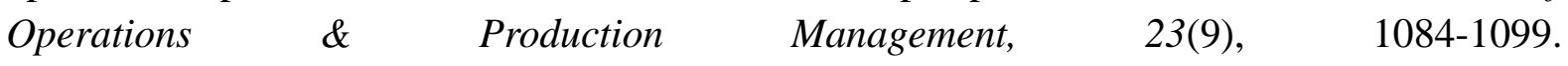
http://dx.doi.org/10.1108/01443570310491783

Mahdavi, I., Mohebbi, S., Zandakbari, M., \& Cho, N. Mahdavi-Amiri, N. (2009). Agent-based Web services for the design of a dynamic coordination mechanism in supply networks. Journal of Intelligent Manufacturing, 20(1), 727-749. http://dx.doi.org/10.1007/s10845-008-0173-6

Mckone-Sweet, K., \& Lee, Y. (2009). Development and analysis of a supply chain strategy taxonomy. Journal of Supply Chain Management, 45(3), 3-24. http://dx.doi.org/10.1111/j.1745-493X.2009.03167.x

Metters, R. (1997). Quantifying the bullwhip effect in supply chains. Journal of Operations Management, 15(2), 89-100. http://dx.doi.org/10.1016/S0272-6963(96)00098-8

Miller, J.G., \& Roth, A.V. (1994). A taxonomy of manufacturing strategies. Management Science, 40(3), 285-304. http://dx.doi.org/10.1287/mnsc.40.3.285

Pasandideh, S.H.R., Niaki, S.T.A., \& Nia, A.R. (2011). A genetic algorithm for vendor managed inventory control system of multi-product multi-constraint economic order quantity model. Expert Systems with Applications, 38(3), 2708-2716. http://dx.doi.org/10.1016/j.eswa.2010.08.060

Pires, S.R.I. (2004). Supply Chain Management: Concepts, Strategies, Practices and Cases. São Paulo, SP: Atlas.

Porter, M.E. (1985) Competitive Advantage. New York, NY: Free Press.

Rainbird, M. (2004) Demand and supply chains: the value catalyst. International Journal of Physical Distribution \& Logistics Management, 34(3-4), 230-250.

Rice, J.B., \& Hoppe, R.M. (2001). Supply chain versus supply chain: the hype and the reality. Supply Chain Management Review, 1, 46-54.

Rother, M., \& Shook, J. (2003). Learning to See: Mapping Value Stream to add value and eliminate waste. Version 1.3. São Paulo, SP: Lean Institute Brazil.

Savaris, C.E., \& Voltolini, E. (2004). Balanced Scorecard Application Model for Supply Chain. Revista da FAE, 7(2), 59-72.

Skinner, W. (1969). Manufacturing: missing link in corporate strategy. Harvard Business 
Review, 47(1), 136-145.

Slack, N., \& Lewis, M. (2002). Operations Strategy. Harlow, Essex: Prentice Hall.

Song, D.P. (2013). Optimal control and optimization in stochastic supply chain systems. London: Springer.

Stock, J.R., \& Boyer, S.L. (2009) Developing a consensus definition of supply chain management: A quantitative study. International Journal of Physical Distribution \& Logistics Management, 39(8), 690-711. http://dx.doi.org/10.1108/09600030910996323

Towill, D.R., Childerhouse, P., \& Disney, S.M. (2002). Integrating the automotive supply chain: where are we now. International Journal of Physical Distribution and Logistics Management, 32(2), 79-95. http://dx.doi.org/10.1108/09600030210421705

Van Landeghem, H., \& Vanmaele, H. (2002). Robust planning: a new paradigm for demand chain planning. Journal of Operations Management, 20(6), 769-783. http://dx.doi.org/10.1016/S0272-6963(02)00039-6

Verwijmeren, M, Van der Vlist, P., \& Donselaar, K. (1996) Networked inventory management information systems: materializing supply chain management. International Journal of Operations \& Production Management, 26(6), 16-31. http://dx.doi.org/10.1108/09600039610125170

Vollman, T.E., \& Cordon, C. (1996). Making supply chain relationships work. M2000 Business Briefing, No. 8, Lausanne, IMD.

Wang, H., Guo, M., \& Efstathiou, J. (2004). A game-theoretical cooperative mechanism design for a two-echelon decentralized supply chain. European Journal of Operational Research, 157(2), 372-388. http://dx.doi.org/10.1016/S0377-2217(03)00233-9

Wanke, P.F. (2010). Logistics for Executive MBA in 12 Lessons. São Paulo, SP: Atlas.

Wheelwright S.C. (1978). Reflecting corporate strategy in manufacturing decisions. Business Horizons, February, 57-66. 